\title{
Correction to: Anatomical Configuration of the Stomach Post-Endoscopic Sleeve Gastroplasty (ESG) What Are the Sutures Doing?
}

Thomas M. Runge ${ }^{1} \cdot$ Juliana Yang $^{1} \cdot$ Lea Fayad $^{1} \cdot$ Mohamad I. Itani $^{1} \cdot$ Margo Dunlap $^{1} \cdot$ Kristen Koller $^{1}$.

Gerard E. Mullin ${ }^{1} \cdot$ Cem Simsek ${ }^{1}$ - Dilhana Badurdeen ${ }^{1}$. Anthony N. Kalloo ${ }^{1}$ - Mouen A. Khashab ${ }^{1}$ - Vivek Kumbhari ${ }^{1}$

Published online: 10 March 2020

(C) Springer Science+Business Media, LLC, part of Springer Nature 2020

\section{Correction to: Obesity Surgery}

https://doi.org/10.1007/s11695-019-04311-7

The name of author Vivek Kumbhari was misspelled in the original article. It is correct here.

Publisher's Note Springer Nature remains neutral with regard to jurisdictional claims in published maps and institutional affiliations.

The online version of the original article can be found at https://oi.org/ 10.1007/s11695-019-04311-7

Vivek Kumbhari

vkumbhari@gmail.com

1 Division of Gastroenterology and Hepatology, Johns Hopkins Medicine, 4940 Eastern Avenue, A Building, 5th floor,

Baltimore, MD 21224, USA 